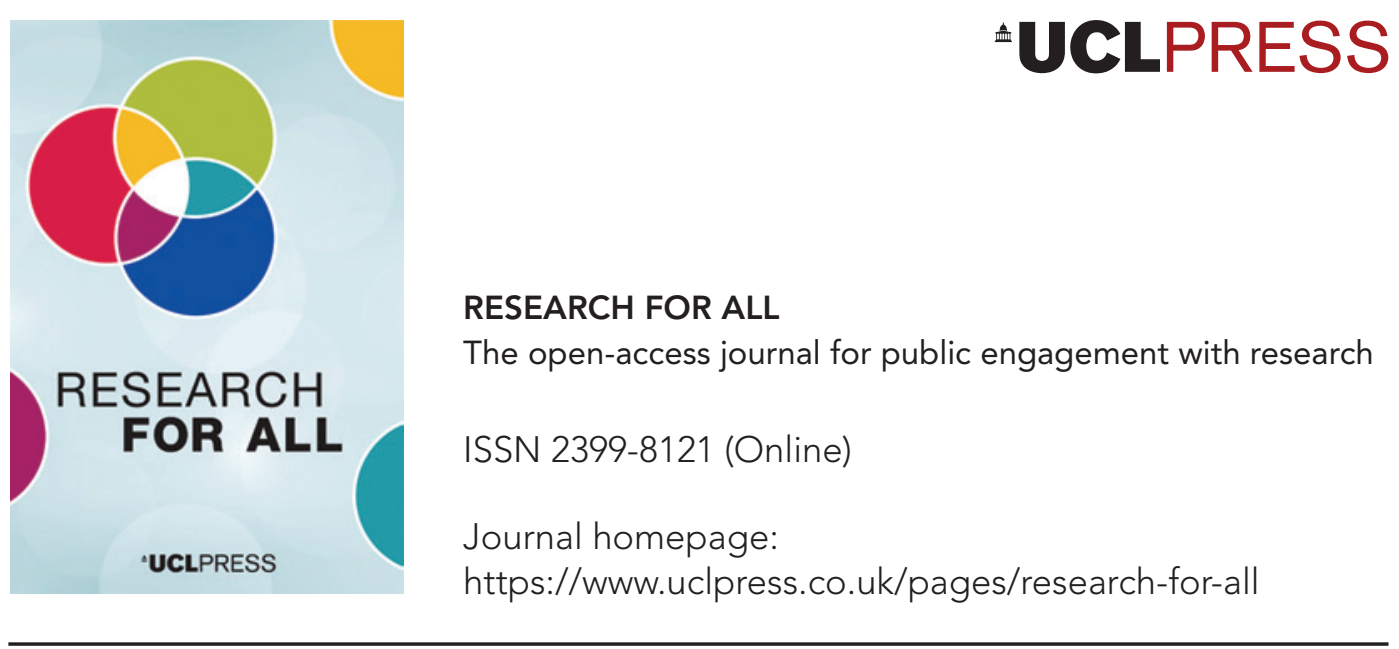

\title{
Future Places Toolkit: Engaging communities through augmented reality and performance
}

\author{
Paul Clarke iD
}

\section{How to cite this article}

Clarke, P. (2021) 'Future Places Toolkit: Engaging communities through augmented reality and performance'. Research for All, 5 (2), 205-26. https://doi.org/10.14324/ RFA.05.2.03

Submission date: 2 November 2020

Acceptance date: 8 June 2021

Publication date: 21 September 2021

\section{Peer review}

This article has been peer-reviewed through the journal's standard double-blind peer review, where both the reviewers and authors are anonymized during review.

\section{Copyright}

(C) 2021 Clarke. This is an open-access article distributed under the terms of the Creative Commons Attribution Licence (CC BY) 4.0 https://creativecommons.org/licenses/by/4.0/, which permits unrestricted use, distribution and reproduction in any medium, provided the original author and source are credited.

\section{Open access}

Research for All is a peer-reviewed open-access journal. 


\title{
Future Places Toolkit: Engaging communities through augmented reality and performance
}

\author{
Paul Clarke* - University of Bristol/Uninvited Guests, UK
}

\begin{abstract}
This article shares processes of engagement with practice-as-research in placebased performance and creative technology, specifically mobile augmented reality (AR). It addresses the application of methodologies from an AR performance, Uninvited Guests and Duncan Speakman's Billennium (2018), in Future Places Toolkit (Clarke et al., 2020), an engagement activity for neighbourhood visioning and planning consultation. It outlines the steps taken to evolve Billennium beyond an artwork into a tool for use in citizen-led design, and to transfer practice-asresearch in performance and technology to a professional architecture and community context, specifically Knowle West in Bristol, UK. By detailing the stages of this research and development process, key learnings will be shared with other researchers seeking to apply their practices to social and civic challenges, and to do so through working in partnership with creative industries and community-based organizations. Future Places Toolkit will be used as a case study to demonstrate the potential of applying approaches from practice-asresearch to real-world problems and developing arts practices into products or services. Documenting and reflecting on the process of prototyping the AR toolkit disseminates procedures for commercializing creative research and leads to a critique of the drive to scale up. Future Places Toolkit is considered as a framework for co-creation with communities and interprofessional partners, and methods for responsible innovation are shared. While these are drawn from responsible technology development, they are transferrable to other professional fields and academic engagement, or to commercialization in different disciplines.
\end{abstract}

Keywords: practice-as-research in performance, augmented reality (AR), co-creation, responsible innovation, speculative design, participatory planning

\section{Key messages}

- Performance and creative technology practice-as-research collaborations can have real-world applications and lead to societal change. In particular, a combination of theatre and augmented reality (AR) tools can facilitate widening participation in neighbourhood visioning and planning consultation, enabling communities to shape the future of their places.

- To ensure successful collaboration and mutual benefit, practice-as-research projects involving different professions, creative industry and community partners must agree on a shared mission and values.

- It is important to consider the ethical implications of co-creating practiceas-research projects with community and industry partners, and then scaling up, commercializing or transferring to new contexts. Responsible technology development methodologies can help to address these issues and could be applied in other engaged research. 


\section{Introduction}

This article shares processes of engagement with practice-as-research in place-based performance and creative technology, specifically mobile augmented reality (AR). It addresses the application of methodologies from the AR performance Billennium by Uninvited Guests and Duncan Speakman (premiered in 2018) in Future Places Toolkit (Clarke et al., 2020), an engagement activity for neighbourhood visioning and planning consultation. Billennium and Future Places Toolkit have both been made with creative collaborators, Jessica Hoffmann of performance company Uninvited Guests (www. uninvited-guests.net/home), sound artist Duncan Speakman (https://duncanspeakman. net/projects/billennium/), creative technologists Michele Panegrossi and Luca Biada (Fenyce, www.fenyce.me), and illustrator and animator Sam Steer (http://samsteer. co.uk/performance/).

Billennium premiered in Bristol's Millennium Square in 2018, having been commissioned by Watershed Media Centre and the University of Bristol's Smart Internet Lab for their Layered Realities 5G Platform (www.watershed.co.uk/studio/projects/ layered-realities), which showcased potential innovative and creative applications of $5 \mathrm{G}$ connectivity to the public (see Figure 1). Billennium is a theatrical guided tour, not of historic sites, but of a city's futures, on which participants walk through time to the locations of utopian and dystopian science fictions. Future architecture appears before participants' eyes, and they hear what different worlds might sound like. Accompanied by performers as archaeologists of the future, participants carry mobile devices that interpret and visualize traces of what is to come (see Figure 2). The tour concludes with an opportunity to design tomorrow's city together and see the imagined buildings layered onto the architecture of today using augmented reality (see Figure 3). Livestreamed, multichannel audio immerses participants in science-fiction location sounds, and speculative architecture is drawn in real time over the existing buildings.

\section{Figure 1: Billennium, Uninvited Guests and Duncan Speakman, Layered Realities, Millennium Square, 2018 (photograph: Jon Aitkin)}

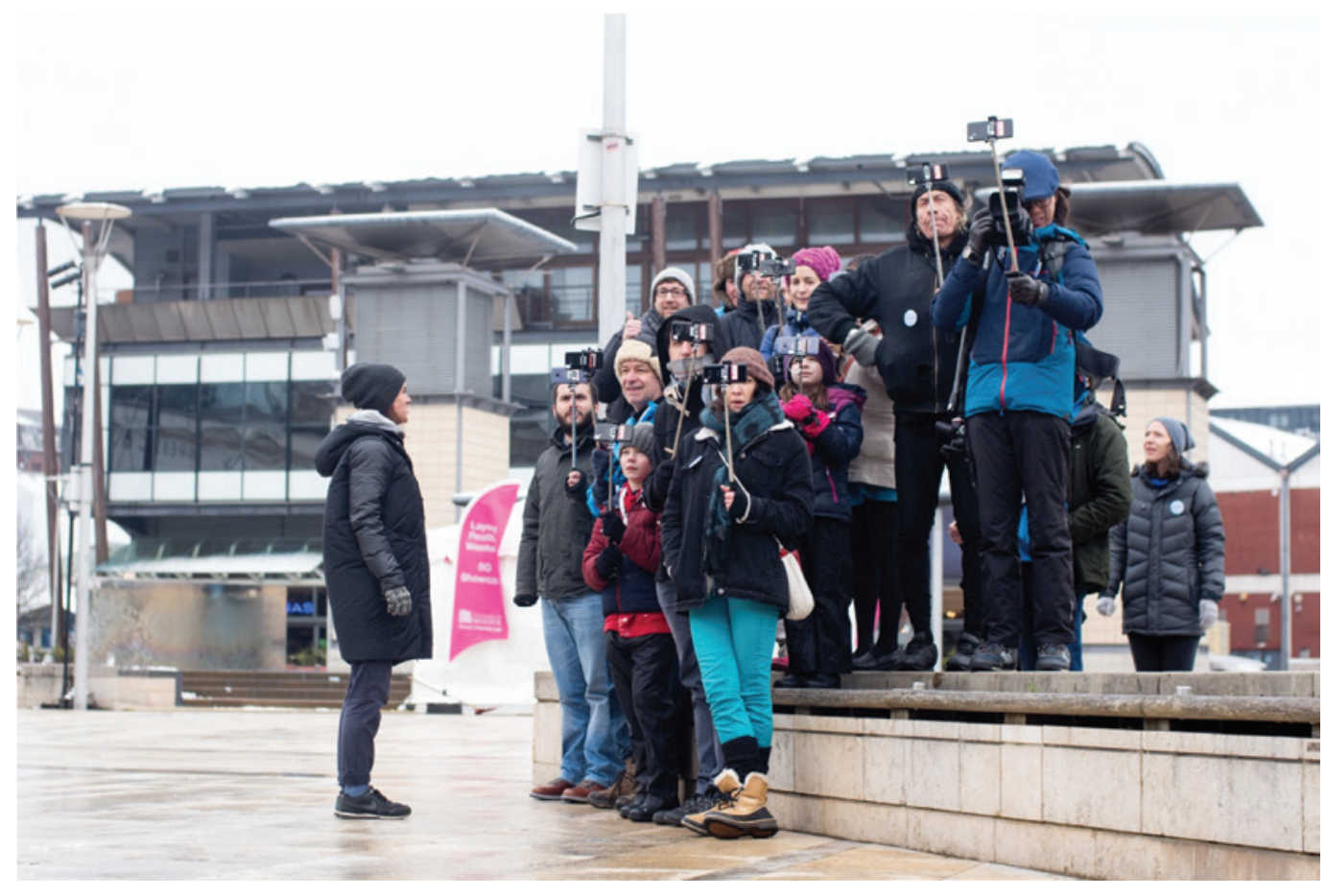


Figure 2: Billennium, Uninvited Guests and Duncan Speakman, Layered Realities, Millennium Square, 2018 (AR animation by Sam Steer; photograph: Paul Blakemore)

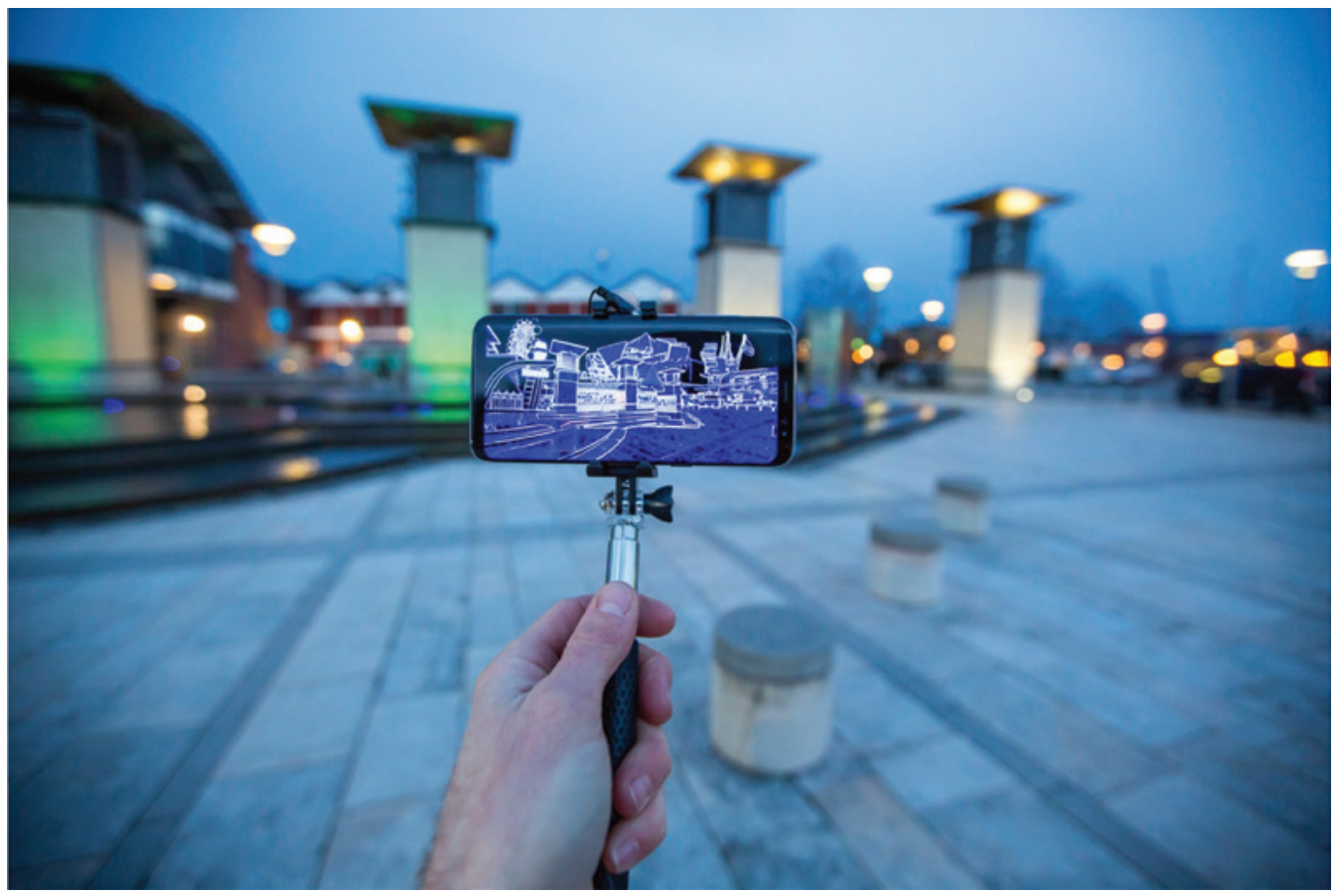

Figure 3: Billennium, Uninvited Guests and Duncan Speakman, Layered Realities, Millennium Square, 2018 (live illustration by Sam Steer; photograph: Jon Aitkin)

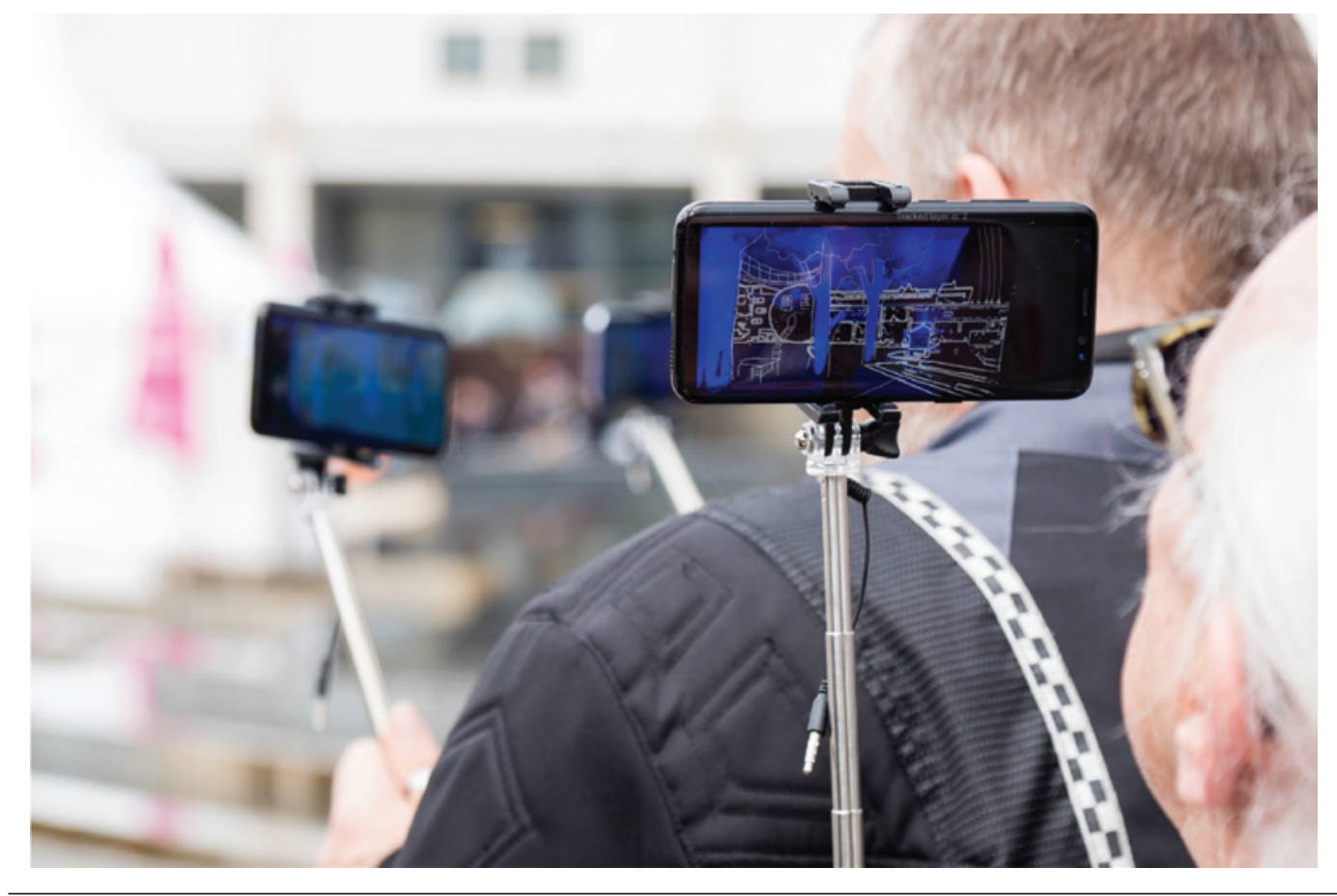

Future Places Toolkit (Clarke et al. 2020), developed between 2019 and 2021, combines guided conversation with an AR drawing app to inspire people to imagine better futures for their places and to visualize them. Drawing on the conclusion of Billennium, 
it is a set of live and digital facilitation tools which enables citizen-led conversations around preferable plans for neighbourhoods. The aim is for the toolkit to be applicable at various stages of a planning and development process, and for it to be scalable and transferable to a range of national and international contexts.

This article outlines the steps taken to evolve Billennium beyond an artwork into a tool for use in citizen-led design, and to transfer practice-as-research in performance and technology to a professional architecture and community context, specifically Knowle West in Bristol, UK. By detailing the stages of this research and development process, key learnings will be shared with other researchers seeking to apply their practices to social and civic challenges, and to do so through working in partnership with creative industries and community-based organizations. Future Places Toolkit will be used as a case study to demonstrate the potential of applying approaches from practice-as-research to real-world problems, and developing arts practices into products or services. Documenting and reflecting on the process of prototyping the AR toolkit disseminates procedures for commercializing creative research and leads to a critique of the drive to scale up. Future Places Toolkit is considered as a framework for co-creation with communities and interprofessional partners, and methods for responsible innovation are shared. While these are drawn from responsible technology development, they are transferrable to other professional fields and academic engagement, or commercialization in other disciplines.

The practice-as-research, creative collaboration and knowledge exchange sought to answer two questions: (1) Can science-fiction storytelling and augmented reality inspire people to imagine preferable, more inclusive futures for their places together?; and (2) Can interactive technologies and performance methods engage a wider range of people in discussing plans for their neighbourhoods, and are these conversations more effective in the sites that are being developed?

Part of the rationale behind Future Places Toolkit was to take Uninvited Guests and Duncan Speakman's work beyond the context of art and technology festivals and the city centre into local communities and the space of participatory architecture. Prototyping has been supported by a Digital Placemaking Fellowship as part of Bristol+Bath Creative R+D, an AHRC (Arts and Humanities Research Council) Creative Industries Cluster. As a term, digital placemaking sounds technical, and could therefore be alienating and exclusive. This knowledge exchange project and the making of the AR toolkit was driven by wanting to engage people who are representative of the margins of the city, and its full diversity, with digital placemaking. The interest was not only in collaborating with creative and industry partners, but also in involving a community in co-designing the performance and technology tools: to co-create an AR engagement activity with the citizens it is being designed for, such that it can help them visualize and shape the future of their built environment. Thus far, one iteration of testing has taken place with community members on Filwood Broadway, a location undergoing significant new development in Knowle West, South Bristol. The article gives a reflective account of this initial engagement experiment with people there, and shares provisional responses to the questions based on these work-in-progress findings.

I will now situate the practice-as-research within the field of performance studies, and by referring to writing on AR and speculative design. Both the performance Billennium and AR engagement activity Future Places Toolkit can be positioned in relation to histories, practices and theories of immersivity and site-specificity in performance. As Mike Pearson and Cliff McLucas write (cited in Pearson, 2010: 4):

... site specific performances are conceived for, conditioned by, the particulars of found spaces ... They make manifest, celebrate, confound 
or criticise location, history, function, architecture ... They are an interpenetration of the found and the fabricated. They are inseparable from their sites, the only contexts within which they are 'readable'.

Although Billennium has toured, its science fictions and accompanying AR animations are site-specific, need to be rewritten and redrawn, and are only readable or viewable in one location. The scripts for both Billennium and Future Places Toolkit draw on historical and contextual research, along with the expertise of local people, which is synthesized with 'fabricated' science fictions that are also responsive to their sites. What is distinctive about Uninvited Guests and Speakman's approach with these works, with regard to other site-specific practices, is that the focus is on futures, rather than revealing the past and layers of history in a place. In their book, Speculative Everything: Design, fiction, and social dreaming, Dunne and Raby (2013: 4) propose that speculative design and science-fiction scenarios are 'aids for critical reflection', in this case on the 'location', 'architecture' (Pearson, 2010: 4) and existing plans for a place.

In addition to the emphasis on futures, a gap in existing site-specific performance practice is explored through incorporating AR technologies. Adam Greenfield (2017: 64) describes AR as 'superimposing' a 'location-specific graphic overlay' on to 'the visual field'. In this way, Future Places Toolkit enables participants to see their preferred plans for the future layered over existing buildings in a site being redeveloped, which would not be possible using less technological methods.

Rather than theorizing AR as blended reality, which would relate to Pearson's (2010: 4) 'interpenetration of the found and the fabricated', Greenfield (2017: 64) discusses 'the conceptual shear between the physical world and the realm overlaid onto it'. With Future Places Toolkit, the contemporary place remains visible to participants, through and alongside the AR drawings of the future on the screens of their mobile devices. They are conscious of the 'shear', and it is in this break or gap that critical comparison can take place between the reality of the neighbourhood now, 'as is', and the 'as if' of the preferable augmented reality future.

According to Greenfield (2017: 64), AR applications are mostly used to 'overlay ... pragmatic information - directions from one place to another, historical facts about a given locale, and so on', but they have also been popularized by the mobile game Pokémon Go, which 'presents players with an alternative reality in which monsters ... inhabit the Earth', and which was a global phenomenon when it launched in 2016. Future Places Toolkit brings the popular genre of science fiction together with AR, and we have found that both are things that a wide range of community members including young people - are interested in engaging with and trying out. Dunne and Raby (2013: 5) argue that such design fictions and speculative methodologies can help 'people participate more actively as citizen[s]' in 'creating more socially constructive imaginary futures', and this aligns closely with the aim of Future Places Toolkit.

Returning to performance studies, Future Places Toolkit can also be considered in relation to the 'social turn', discussed by Shannon Jackson (2011) in Social Works: Performing art, supporting publics, as well as alongside the immersive and participatory forms analysed in Fair Play: Art, performance and neoliberalism (Harvie, 2013), including previous works by Uninvited Guests. The most appropriate performance studies paradigm for the practice-as-research outlined here is probably what Andy Lavender (2016: 3) calls 'theatre of engagement', which 'entail[s] ... altered modes of engagement on the part of both practitioners and spectators', who 'become participants'. He considers works by artists such as Rimini Protokoll and Dries Verhoeven, which involve 'particular communities' with shared 'interest' (Lavender, 2016: 28) or lived expertise, and which are often hybrid or 'intermedial' (Lavender, 2016: 4). Like Future Places 
Toolkit, they integrate 'high-tech ... component parts and media' (Lavender, 2016: 27) to facilitate 'new forms of interaction ... between' performer, participating spectator, event and place (Lavender, 2016: 3). For Lavender (2016: 26), this is 'socially committed' theatre that is 'turned towards [its] society, deliberately invested in social processes, ... [and] matters of import to [the] groups of people' gathered. It sets up situations or conditions in which there are 'opportunities for people to speak for themselves' (Cohen-Cruz, 2010: 4, cited in Lavender, 2016: 28), particularly those who do 'not have so public a voice' (Lavender, 2016: 28).

\section{From AR artwork to applications in architectural design}

After being shown in Bristol, Billennium (2018) was commissioned for STRP 2019 (https://strp.nl/program/augmented-reality-tour-billennium), the festival of art and technology in Eindhoven in the Netherlands. The success of the AR performance at STRP led to us being invited back to Eindhoven to present as part of Dutch Design Week 2019 (https://www.strp.nl/events/strp-at-dutch-design-week). This gave us the opportunity to showcase our work in a commercial design context, rather than at an arts festival, and persuaded us of its possible applications in participatory planning and urban design.

In preparation for Dutch Design Week, we put together evaluation forms to provide us with testimonies from participants, and to help us build an evidence base for further touring and funding opportunities. We received 69 feedback forms, of which 62 said that they had never experienced anything like this before. They said the methods 'sparked their fantasies' and encouraged 'speculative thinking about the place'; the performance 'allow[ed] participants a role in it', and empowered them to collaborate on inventive ideas for the future of their city. Participants wrote that the approach was 'really unique', and one said, 'I had no idea how the world would look in the future, but now I suddenly have tons of ideas.' A number of those who participated at Dutch Design Week noted that Billennium could be used effectively in urban planning.

We received similar comments in Bristol, and this feedback made us consider whether aspects of Billennium could be useful beyond the art world - if our fictional or theatrical methods could be practicable in actual situations, and have civic or social impact. Billennium was created as an artwork, but in each of the contexts in which we have shown it, people have identified real-world applications, in particular its potential to engage local communities with planning consultation.

This led to me applying for a Digital Placemaking Fellowship (Bristol+Bath Creative R+D n.d. b), the first Pathfinder on the Bristol+Bath Creative R+D AHRC Cluster. The enquiry that I proposed set out to explore whether Billennium's interactive performance and creative technology approaches could be used in neighbourhood visioning, participatory building design and planning. I will now introduce the concept of digital placemaking and the fellowship.

\section{Digital placemaking}

Digital placemaking concerns the interplay between physical and digital worlds in public space. It considers places as hybrid physical-digital, and addresses the ways in which offline and online spaces, the public realm and the private infosphere have become entangled. For Dr Jo Morrison, Director of Innovation and Research at mobile app developer Calvium, and consultant on the Pathfinder, digital placemaking is about 'using location-specific digital technology to foster deeper relationships 
between people and the places they inhabit'. It involves the 'augmentation of physical places with' digital layers, 'services, products or [interactive] experiences', and has the potential to 'enhance or even radically transform an individual's experience of their time' in a location (Morrison, n.d.: n.p.).

In her 'Digital Placemaking Guide', Morrison (n.d.: n.p.) says that 'digital placemaking is focused on making places better', and has the potential to 'boost [their] social, cultural, environmental and economic value'. The aspiration to augment places digitally in order to make them better is positive, but it is important to keep asking, better for whom, and for who is value added? Who are the technological tools or platforms made with and for? Who can shape and participate in making a city's digital places and layers? These are issues around inclusion that I endeavoured to keep in mind in my practice-as-research, and they drove both the interest in processes of co-design and the choice of community with which to engage.

The fellowship on the Digital Placemaking Pathfinder enabled me to survey theories of speculative design and design fiction methodologies, and to explore futures as critical tools and how writing collaborative science-fiction stories in specific places could be a way of prototyping.

The Pathfinder brought together industry, new talent, inclusion and academic fellows such as me, with industry partners, including BBC R\&D, City ID, Stride Treglown architectural practice, and Niantic, the makers of Pokémon Go. The fellows selected had diverse professional and lived experience, but the cluster's producers established a space with little hierarchy that modelled best practice, in which everyone's ideas, from industry partners to new talent fellows could be heard. In a series of workshop activities, presentations and Open Space Technology meetings, we interrogated our definitions of placemaking, introduced inclusion practices, and shared emerging technologies, platforms and challenges for the industry, along with exchanging methods of co-creation. With support from the Bristol+Bath Creative R+D producers, we also identified our target audiences and how to reach them, and focused our research enquiries and methods.

Through this process of workshopping, I developed a productive exchange with architects Stride Treglown and Digital Placemaking inclusion partners Knowle West Media Centre (KWMC). This led to Uninvited Guests partnering with them and our creative collaborators on successful applications to the University of Bristol's Knowledge Exchange Fund and for research and development funding from Bristol+Bath Creative $R+D$ to develop a prototype of Future Places Toolkit.

\section{Addressing civic and industry challenges through performance and technologies}

Future Places Toolkit seeks to apply creative practices and immersive technology solutions to challenges identified by our architecture industry partners around public engagement with planning processes. Rob Sargent, Director of Stride Treglown, noted that planning consultation can be perceived as dry, and that there can be a problem with engaging a broader range of people with neighbourhood visioning. For him, the Toolkit could enable developers to understand the vision of a community before they purchase potential sites, leading to proposed developments being more civic and aligned with local needs. Rather than communities feeling excluded and disenfranchised by developments that are parachuted in, they would feel listened to, be able to have an impact on development briefs and buy into more positive, inclusive plans for their neighbourhoods, which they were involved in developing. 
We have also partnered with KWMC's We Can Make citizen-led housing initiative, to develop the project (https://kwmc.org.uk/projects/wecanmake/). For Melissa Mean, of KWMC, writing in the proposal for Future Places Toolkit, this approach addresses 'legitimate feelings of lack of agency in consultation, people defaulting to a position of Not In My Back Yard', and has the potential to 'create a non-hierarchical space for discussion between all the stakeholders'.

Consultation with local residents tends to take place away from the site of the development itself, with plans being displayed in community centres or town halls. Future Places Toolkit allows collaborative drawings to be viewed layered over existing buildings, and for conversations to happen in situ, between members of the local community, council planners, architects and developers. The entertaining and engaging approach aims to get more representative people involved in sharing hopes and dreams for their place in a situation without hierarchy: everyone's stories about the future will be heard and the architecture they describe will be visualized immediately around them using AR (see Figure 4 and Figure 5). Live spatialized sound will bring their ideas to life, giving their future places atmosphere and supporting their imaginings. Future Places Toolkit lets participants see, hear and experience different futures, making them more tangible and giving people a better sense of what they would be like to live in. In this way, we hope to help people understand and influence decisions about plans for their neighbourhoods. Ultimately, the aspiration is to feed into better development briefs and for people to have more impact on the design of their public realm and what is built.

As our aim for the engagement activity is to be inclusive, barriers to access are being considered throughout, along with issues of equity in terms of access to hardware and digital literacy for software usage. Therefore, suitable mobile devices will be provided for participants as part of the service, and the AR app does not require users to touch their screens but simply to interact by moving the device around to see the AR world on which they are collaborating.

\section{Figure 4: Example live illustrations by Sam Steer, from Billennium, Uninvited Guests and Duncan Speakman, Layered Realities, Millennium Square, 2018}
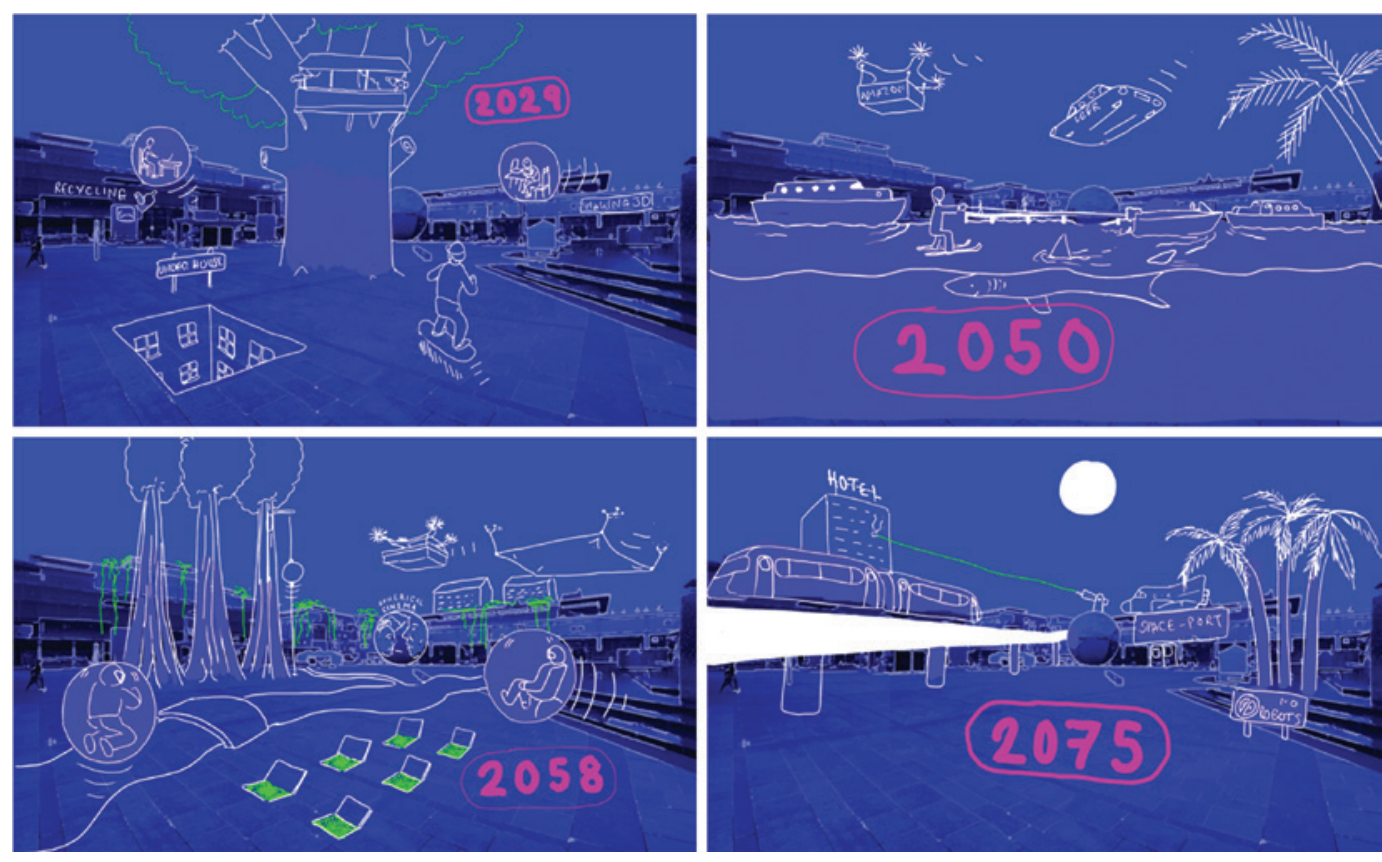
Figure 5: Example live AR illustrations by Sam Steer, from Billennium at Dutch Design Week 2019, Eindhoven, the Netherlands
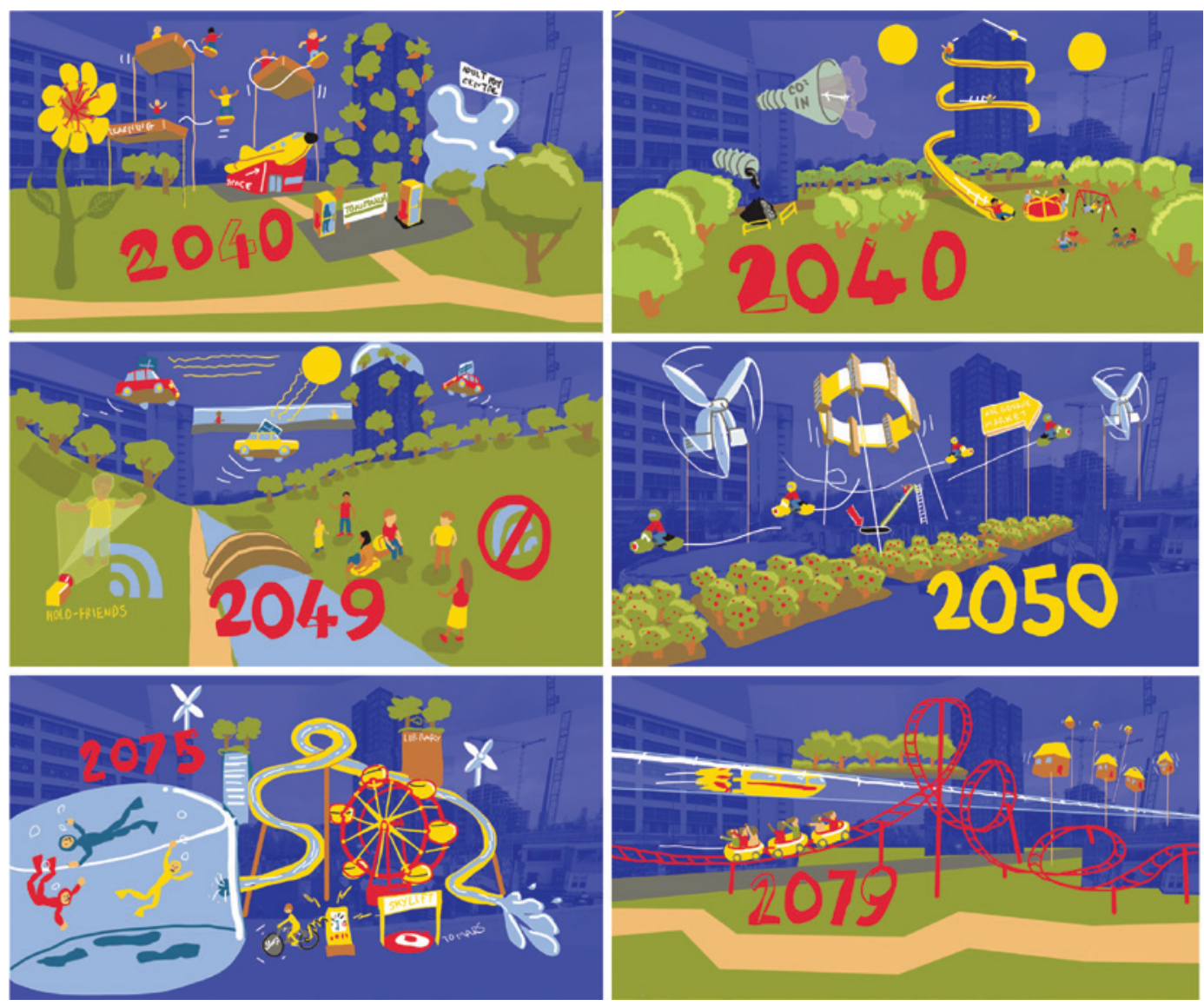

\section{Responsible technology development}

For us, one of the most influential inputs during the Bristol+Bath Creative R+D was a workshop with Alex Mecklenburg, then of Doteveryone. This organization was imagined by Martha Lane Fox to 'put the public at the heart of the conversation around technology and help navigate the new [ethical] challenges that technological change poses for society'. For the last five years, they have demonstrated the importance of developing technology responsibly, the 'need to change how tech is made and used, so that it works in the best interests of people, communities and the planet' (Doteveryone, 2020: n.p.).

Although Doteveryone drew their work to a close in May 2020, I would highly recommend exploring their practical resources for innovating responsibly, which are now hosted by the Open Data Institute. A wide range of knowledge exchange or commercialization projects could benefit from their responsible development practices, especially those that involve a service design process or that could lead to a digital product. In particular, Alex Mecklenburg introduced us and the teams developing digital placemaking prototypes to 'consequence scanning'. A how-to manual for running your own event can be downloaded from the Doteveryone website (Brown, 2019).

Since we found this new development practice very constructive, we invited the Future Places Toolkit project team, collaborators, partners, critical friends, advocates 
and key stakeholders to come together for a workshop inspired by Doteveryone's approach. As recommended, we ran this event at the start of our collaborative process, the 'initial conception of the product', and as a way of marking the beginning of our iterative development.

\section{Shared mission and values}

We started with each participant - individual, company or organization - sharing their interest in the project and what they wanted to get out of it. Then we collaboratively edited a mission statement that we had drafted. Initially, this led to a semantic dispute about what it should be called, with some having a preference for 'vision' over 'mission', and others suggesting 'purpose', or a set of principles that govern how the Future Places Toolkit service or product behaves.

This is the co-created text which we arrived at:

To enable inclusive and imaginative conversations about the future of places between communities and stakeholders. To empower people to have influence over the future of their neighbourhood.

Originally, it said, 'to empower people to have agency'. 'Agency' is often applied to participatory performance such as that of Uninvited Guests, in the immersive technology context of Fenyce, and by organizations such as Knowle West Media Centre, which explores creative models for social change. However, Rob Sargent of Stride Treglown suggested that 'agency' is not a word in common use among architects. This highlights the importance of interrogating specialist terms when working with interdisciplinary teams and developing shared language.

KWMC, who developed The Bristol Approach, a set of guidelines for co-creating tools to address the digital divide and issues identified by citizens (King et al., 2020: 211), state that, 'at the start of every project, it is essential to give time to defining and co-creating a shared mission of change ... a clear headline intent' (King et al., 2020: 207). While the different actors involved in our project had various interests in working together, and various aims and agendas, it was important to share common values and principles, and an ethos that would be abided by, inspire and build trust in the collaboration.

\section{Consequence scanning}

I will return to co-creation, but first I want to introduce consequence scanning, my account of which will speak to a possible tension for knowledge exchange projects, which involve partnering with profit-making businesses, around responsibility for, and control of, the future use of data collected and the product created together.

Doteveryone suggest that consequence scanning is a good way to shift from 'big, abstract conversations about ethics and values into something more tangible in the context of the product you are creating' (Brown, 2019: 6). In this part of our workshop, we asked, 'What are the intended consequences of the product or service?' and 'What could the unintended consequences be?' The intended consequences 'are the change or impact you are looking to make', your intent and what you want to be responsible for. Both intended and unintended consequences can be positive or negative. All the participants came up with these individually to start with, generating consequences for Future Places Toolkit or its features, and writing them on different coloured Post-it Notes to represent intended and unintended consequences. Then we categorized the impacts, determining whether they were for: the makers, 
partner organizations and companies; the user and people who are engaged; the wider community or neighbourhood; more broadly, for society and the sector, other architects, consultants, council planners or policymakers; and finally noting any impacts on the planet or environment. Consequences were then sorted into groups according to affinities, and were discussed. We addressed the positive consequences which we would collectively like to focus on, prioritize and bring forward. Then we moved on to the potential negative consequences and what we could do to monitor or 'mitigate any potential harms, to [collaborating artists, businesses and partners, to our] users, and to the communities [we] operate in' (Brown, 2019: 10).

Outcomes of this consequence scanning were interrogated further during mentorship sessions with Alex Mecklenburg for the core development team. For instance, one participant noted the unintended consequence of what they called 'conceptual asset stripping', the mining of the community's ideas by architects or developers, taking people's creative intellectual property without appropriately crediting it. Alex asked whether 'it was our responsibility to ensure mutual value' that the activity would benefit both those for whom we were running the consultation (council, consultation company, architects or developers) and the people/community participating. This fed into our scripting of the preface to the engagement activity/ experience, which we recognized needed to be transparent about what would happen to people's data and the ideas they imagined, along with how they would feed into the public consultation, and what influence they could have on the development plans or neighbourhood vision. The intention is, as Paul Seaver of Stride Treglown said, 'to contribute usefully to the Statement of Community Involvement (SCl) that accompanies a planning application'. This documents how local residents, businesses, community and interest groups have been involved in deciding on plans, and whether those who will be affected accept the proposals and have had the opportunity to improve them.

If, as Rob Sargent proposed, Future Places Toolkit enables communities to influence and improve development briefs, leading to proposals over which communities have a sense of ownership, and which are 'aligned with local needs', then contributing to the $\mathrm{SCl}$ is a positive consequence. But, as Horvath and Carpenter (2020: 5) note, there is 'the risk of co-option' for co-creation methods: in our case, that the engagement could be data mined by developers for evidence of local buy-in for plans that lead to gentrification, to displacement, or to the character of a neighbourhood changing in unwanted ways. Going forward, if we are to take Future Places Toolkit to market, we should monitor this. The way of mitigating it is to clearly articulate our principles in publicity materials and only to partner with civic-minded developers with shared values. It is certainly important to recognize the risk of becoming complicit in gentrification, 'art-washing' and generating community buy-in for contested schemes, a criticism that Stephen Pritchard (2016) has made of creative placemaking.

\section{Architecting: Exchanging expertise around design and planning}

We continued to hold regular meetings with architects at Stride Treglown, workshopping Future Places Toolkit with Senior Associate Urban Designers, Sarah Jenkinson and Paul Seaver, as well as Rob Sargent.

In light of our mission and initial conversations, in a personal email communication, Sarah Jenkinson raised the issue of how to maintain the 'balance of inspiring creativity' alongside developing 'a tool that is effective in built environment [design] processes and [satisfies formal] requirements'. For her, it was important to return to 
the fundamental questions: 'What is it that we are offering?', and 'What do we want, or have the capacity, to deliver?' By this, she was addressing whether Future Places Toolkit is an end-to-end consultation process, or an engagement activity that would ideally be offered at a specific stage. As practitioner-researchers and creatives, are we interested in processing the data from feedback, analysing priorities and presenting reports? And would we want to be responsible for preparing a pre-application Statement of Community Involvement? We would be able to document our Future Places Toolkit public consultation activity, and evidence how the community were engaged in a meaningful way through it. We could collate and present their feedback in an imaginative, visual way. However, we might not want to summarize the findings, draw conclusions and make recommendations, or outline the design responses. This might require having a professional architect or planning graduate on the team, which would only be feasible if we scaled up. So, Sarah suggested that we initially offer our in-location AR engagement event to established community consultation companies which share our values, for instance Make:Good, 'an architecture and design studio involving people in shaping neighbourhood change'. That way, we could work with them to encourage 'positive participation in local change', but also to 'effectively communicate [the] ideas and share [the] insight', as the Make:Good website states (Make:Good, n.d.: n.p.).

Paul Seaver suggested that we take a look at the RIBA Plan of Work, which is a 'framework for architects to use on projects with their clients' and explains the different stages of a building project and planning tasks (RIBA, 2020). That way, we could use the correct industry terms when promoting Future Places Toolkit, which returns us to the importance of developing shared language, but in this case exchanging knowledge of expert language. In email correspondence, Sarah Jenkinson proposed key questions to which she would want to know the answers as a potential client, and she worked with us to develop pragmatic responses.

The other thing that came up when exchanging with Stride Treglown was the importance of setting clear and realistic expectations about the scope of the activity. This returns us to the ethical issues raised by Alex Mecklenburg in relation to responsible technology development. In her email, Sarah Jenkinson articulated the aim of the activity as being 'to inspire creativity in, and unlock the aspirations of, local people'. She recommended that it would be important to clearly explain the boundaries, 'so that the activity isn't misleading' for participants 'in terms of its purpose and outcomes'. She anticipated clients wanting to know that we would make 'clear where the community have the ability to influence placemaking decisions and also why certain ideas can't be taken forward'.

Stride Treglown felt that there could be a range of additional benefits, for instance co-creating clear objectives to refer to throughout the development process, building trust and relationships between consultants, stakeholders and the community from the start, and enabling engagement to be proactive rather than reactive. In particular - as was borne out later by testing in Filwood - the AR app encourages participants to say what they want for the site, and then to move rapidly into positive discussion about what it could be like, rather than speaking negatively about what they do not want. One aspect that Sarah Jenkinson was interested in exploring was whether the benefit of Future Places Toolkit lies in bringing the community together to hear one another's opinions, or if it could, in fact, be a tool for consensus-making.

Consultations with urban designers at Stride Treglown were very valuable in terms of exchanging knowledge: we are now in a position to prepare a promotional document that effectively markets Future Places Toolkit to clients, and answers 
questions that they are likely to frequently ask. While it may be necessary to include some technical language from design and planning, a key learning has been to try to use the same plain language for everyone, so that all stakeholders in a process are on the same page.

\section{Scoping, research and software development}

COVID-19 and the March 2021 lockdown prevented us from beginning iterative testing in person as early in the process as we had intended. This led to a shift in the development timeline and milestones, so that the initial emphasis was on scoping, research and design of a technology demonstrator and facilitation tools based on the functionality of Billennium.

Jessica Hoffmann and I surveyed other influential projects engaging with participatory futures and critical hypothesizing, while consulting with the architects about questions and provocations that would form part of the facilitation script. As a company, Stride Treglown also carry out research, and we drew on 'Shaping future places' (Stride Treglown, n.d.), along with The Little Book of Provocations (Stride Treglown, 2018), which summarized this initiative, as well as Paul Seaver's analysis of the components of place in a personal email communication: 'things we try to think about with [stakeholders] when it comes to designing or regenerating places'. As we could not get together in person, we also met with the creative technologists via Zoom to do some paper prototyping of the app, and to journey map the experience of participants through the consultation activity, borrowing both methods from service design.

We focused on how to guide the conversation in useful and inspiring ways, while Panegrossi and Biada (Fenyce) explored network solutions, including using a portable $4 \mathrm{G} \mathrm{Wi-Fi} \mathrm{router} \mathrm{rather} \mathrm{than} \mathrm{5G,} \mathrm{for} \mathrm{ease} \mathrm{of} \mathrm{connectivity} \mathrm{in} \mathrm{most} \mathrm{locations.} \mathrm{They}$ programmed the drawing software and mobile app so that the artist could draw the participants' speculative ideas remotely, and scoped out the best platform/software development kit (SDK) for effectively blending the digital future worlds imagined and the physical place.

Panegrossi and Biada moved away from the marker-based approach to AR tracking that we had used in the performance Billennium in favour of an 'anchor'based system: the phones use their built-in cameras to recognize surfaces and create a $3 \mathrm{D}$ version of the surroundings that can be synched across multiple devices. So, rather than only looking at a scene from a single perspective, as in Billennium, Future Places Toolkit enables users to turn 360 degrees and to see visualizations appear all around them. They are also able to move physically within the virtual 3D environment, instead of solely seeing their drawings at a distance. This will make it possible to place content created in 3D instead of 2D, to give participants additional agency, and to make the experience more immersive (see Figure 6). The aim is also to enable architects to upload existing designs, so plans can be seen, discussed and adapted in situ. Ideally this will be integrated with Building Information Modelling (BIM).

Panegrossi and Biada are also exploring how the visions that each group of participants have drawn can be displayed using the AR app for others to browse through, interact with and explore in the site. While the focus is on presenting in the place, we want to make the 3D sketches, and the annotations of them with people's science-fiction imaginings, viewable online. In that way, the consultations will be documented, and a community's hypothetical proposals, their hopes and dreams for their place, can be made accessible remotely - for developers or the council, for instance, and also for those in the community who are unable to participate in person. 
Figure 6: 3D objects placed in augmented reality (screenshot: Luca Biada)

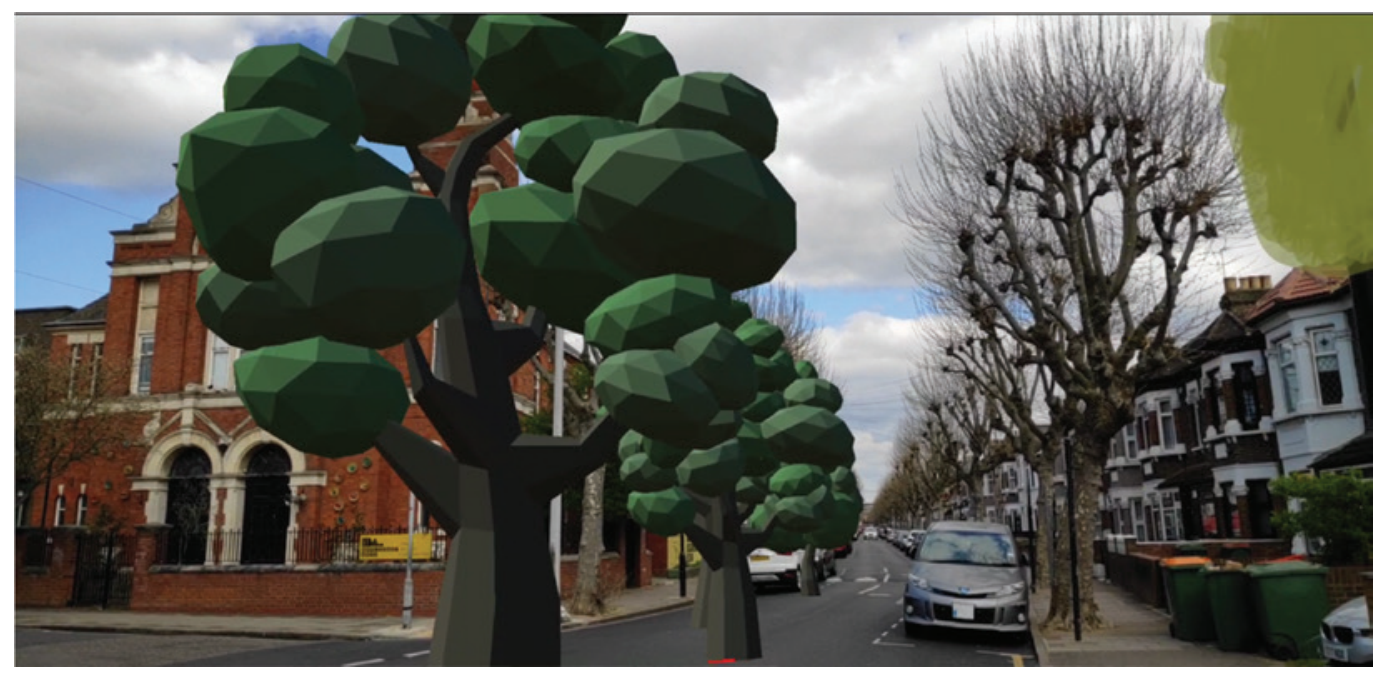

\section{Co-creation and iterative development}

I have discussed co-creating a Future Places Toolkit vision, or mission statement, and co-designing the toolkit with creative technology collaborators and architecture partners. One of the Core Values of Bristol+Bath Creative R+D (n.d. a) is co-creation, with the cluster website stating that they intend to 'bring in users and partners as co-commissioners and co-designers of challenges'. Similarly, Stride Treglown (n.d.: n.p.) state that 'future places should be shaped with and by their communities' by 'joined-up thinking on the social, economic and technological issues they face', and 'by joined-up doing from people across different disciplines, sectors and areas of expertise'.

One of the shared values of the Future Places Toolkit project team is also 'to co-create and test ground-up, citizen- and community-led approaches, without hierarchy'. My applications to the Knowledge Exchange Fund and for Bristol+Bath Creative R+D funding proposed that Future Places Toolkit would be designed with and for its users, and iteratively tested with different publics in real-world contexts. We aimed to employ an agile development process, adapting software features and facilitation techniques in response to user feedback and evaluation of our engagement experiments. Agile refers to iterative software development methods 'where requirements and solutions evolve through collaboration between selforganizing cross-functional' or cross-disciplinary teams, through which features are delivered incrementally, rather than all at once. It encourages 'frequent [trials] and adaptation' and 'aligns development with customer [or user] needs and company [or project] goals' (cprime, n.d.: n.p.).

Our partners, Knowle West Media Centre, provide a useful definition of cocreation as: 'a cooperative process whereby people with common interests, often with diverse skills and experiences, work together non-hierarchically towards a change they want to bring about' (King et al., 2020: 207). What we are developing in a participatory way, drawing on co-creation techniques, is itself a tool for co-creation, which 'employs creativity through arts-based methods'; in this case, science-fiction storytelling and our artist's live visualizations (Horvath and Carpenter, 2020: 4). The co-produced product or service aims to get people with different backgrounds and knowledges - including local knowledge - involved in generating research data about preferred futures for a place. 
I now turn to Campbell and Vanderhoven (2016) to sum-up 'the potential of co-production' and why knowledge from meaningful exchange matters. They write that co-created 'research is undertaken with people rather than on people', it is 'a collaborative, iterative process of shared learning'; the relationship of researcher and participants is not 'extractive or transactional', but rather 'interactive'. This approach to engaged research blurs the 'boundaries between ... academic and non-academic' (Campbell and Vanderhoven, 2016: 12). KWMC similarly argue that impact should not only be one way, on the public and communities; it should also be on researchers, the project, business partners and institutions (King et al., 2020). In co-production, all of these partners and relationships undergo change, and exchanges can impact on the framework and lead to new or altered research questions. This relates to Anna Tsing's (2015: 38) critique of scaling up, and the idea of 'nonscalability', which I will now address.

\section{Scaling up and nonscalability}

As the Creative Industries Cluster Programme is funded by the Industrial Strategy Challenge Fund, one of its aims is to 'accelerate growth in a range of creative sectors' and to 'drive the creation of companies, products and experiences that can be marketed around the world' (UKRI, n.d.: n.p.). Bristol+Bath Creative R+D takes an approach that focuses on inclusive and sustainable growth, but the cluster is still looking to fund cultural platforms, digital services and marketable applications that are created by regional teams but have the potential to be delivered at scale. Hence, in my request for follow-on funding for the fellowship project, I argued that I would explore the commercialization of Future Places Toolkit, ways of scaling this service or product, and routes to market, nationally and internationally.

I want to talk about the drive towards accelerating growth, 'rapid prototyping' and to 'scale up innovation', which is also present in the aims of the European Network of Living Labs (ENoLL, n.d.), of which Knowle West Media Centre is a member. If a project, platform, model, product or service scales well, it is able to perform as effectively when its scope and workload are expanded, and in different contexts, without needing changes to be applied. Growth is linear, and suggests that income increases at the same pace as the amount of labour and investment put in. If the system developed is scalable, revenue can be added more efficiently, at a far greater rate than the time and resource cost to the developers. Scalability is often the aspiration when arguing for the commercial potential of university research and knowledge exchange projects.

While there might be quantitative and financial benefits in utilizing the language of scalability, it is important to consider the potential qualitative loss from scaling up, and what cannot be smoothly scaled. Anna Tsing (2015: 39) suggests that in research, to 'scale up' involves 'the ability to make one's research framework apply to greater scales, without changing the questions' and, for her, it has become the 'hallmark' of contemporary knowledge production, not only of expansionism in platform capitalism. She tries 'to build a critical distance from scalability', suggesting a 'scalable business ... [that] does not change its organization as it expands' is only possible 'if business relations are not transformative', if the business model - and by implication their piece of technology or platform - does not change 'as new relations are added' (Tsing, 2015: 39). Elsewhere, Tsing (2012: 505) likens technology companies' 'ability to expand - and expand, and expand - without rethinking the basic elements' to digital media's 'power to make the great tiny and the tiny great in an effortless zoom'. Think of the universality, consistent aesthetic and powerful functionality of Google Maps and Street View. Tsing argues that such platforms get in the way of 'our ability to view the 
heterogeneity of the world'. It is the homogeneity of such mapping applications that PopMap, one of the digital placemaking prototypes made by City ID and Calvium, attempts to counter, with the idea of a local platform, which changes temporally and has a bespoke city-specific aesthetic. To use 3D Building Information Modelling in architecture as an analogy, as you zoom out, in fact, you decrease the scale of the model, view at a lower level of detail, and lose accuracy and refinement.

In order to 'allow smooth expansion', a scalable research project or digital service would need to exclude 'the indeterminacies of encounter' and the kind of 'meaningful diversity ... that might change things', and require adaptation of the underlying framework or platform (Tsing, 2012: 507). So, efficient, financially viable research and development could necessitate removing from consideration stakeholders, users or citizens who behave in diverse, unpredictable ways, and not engaging in meaningful ways with 'real life communities and settings' (ENoLL, n.d.: n.p.). Hence, scalable design could involve decentring citizens/users with radically different life experiences, backgrounds or knowledges, along with neighbourhoods that have less social capital. This could lead to denying access to R\&D, and also to the technological tools produced, for those who have already been marginalized, are underprivileged and under-represented, thus exacerbating existing digital inequities.

Anna Tsing discusses 'nonscalability' (2012: 505), and while developing Future Places Toolkit it has been important to consider which aspects are not scalable and will need to be changed in relation to the specifics of each new physical and social location. While Future Places Toolkit is modular, and parts of it - especially the AR drawing app are designed to be flexible and transferable to a range of contexts, it is important to acknowledge that elements of the toolkit will not be universally usable or applicable. As users, real-world settings, communities and their challenges are not interchangeable, the service will need to continue to be agile and responsive to each new site or iteration. In relation to Tsing's (2012) critical take on scalability, and on which communities tend to have privileged access to R\&D, I would note our decision to exchange knowledge and expertise with KWMC, and to engage with Filwood, an area of Bristol that 'ranks highly in government indices of deprivation' (King et al., 2020: 209).

Care will need to be taken to localize the Future Places Toolkit service to each new site and situation. As Paul Seaver of Stride Treglown noted in his personal email communication, the components of place - points to think about with stakeholders and questions asked would need to be 'adapt[ed] to suit each setting', and the remit of the consultation. In terms of transferability, as well as inclusive development, it must be acknowledged that, as Doteveryone write in their consequence scanning manual, 'not everything about what you create is going to be good for everyone in every context', but responsible technology developers should 'mitigate any potential harms ... to the communities you operate within' and reduce barriers to access for participants or users (Brown, 2019: 10).

\section{Testing with Knowle West Media Centre on Filwood Broadway}

In early August 2020, collaborators on Future Places Toolkit were able to meet in person for a residency at KWMC and Filwood Community Centre, and to carry out our first iteration of testing with the initial version of the AR app. Having limited participants to six at a time and put in place COVID-safe measures, such as social distancing and sanitizing selfie-sticks, we ran two rounds of public tests. We worked with producers at KWMC to engage local residents, community organizers and people from various 
teams at the Media Centre. We also collaborated with three different illustrators over the week: Andy Council, Camille Aubry and Sam Steer. They joined us at the Community Centre, or worked remotely, and they were able to offer user feedback on the functionality of the 3D drawing software, the drawing tools and interface (see Figure 7).

Bristol City Council is currently looking at the regeneration of Filwood Broadway, and they have been inviting people to have their say since December 2019. Originally built in the 1930s, the Broadway' is located at the heart of Knowle West and has historically played a central role in providing services for the local community', but it has suffered from lack of investment and the loss of many of these facilities (The Knowledge, 2021: n.p.). Shortly before lockdown, on 13 March 2020, we attended a public consultation event run by Knowle West Alliance and Knowle West Future, which offered the local community the opportunity to view, influence and shape the development briefs and designs. Redevelopment plans were displayed, along with analysis of the sites, planning constraints and why the council is supporting building in this location. The reasoning focused on helping to meet demand for more housing in the city and area, particularly social and affordable homes. The current plan is for a mixed-use scheme, mostly residential with a mix of new council housing, shared ownership and private homes, with an opportunity for community spaces and commercial frontage on the Broadway. This consultation took place in Filwood Community Centre at the end of Filwood Broadway, and used analogue means, a map of the neighbourhood, pens and Post-it Notes, to gather and place participants' issues, needs and wants for their area.

We were able to draw on these when we introduced Future Places Toolkit, contextualize the engagement activity in relation to the ongoing City Council consultation and how they aim to develop the land, along with providing some historical information, such as how Knowle West was constructed on garden city principles. Thus, the framing of our physical-digital and social service was localized (rather than personalized) and custom made for the specific situation, community and site.

The engagement activity began with an imaginative journey from 2020 and the time of the pandemic, out of participants' present-day concerns and everyday realities, further and further into the future. To a Bristol-specific science-fiction soundtrack, they were encouraged to think about how the city and world beyond Knowle West might differ, and to visualize the buildings around them changing.

We used prompts in our facilitation script to guide the conversations. Some of these provocations urged participants to engage with social and civic challenges or to

\section{Figure 7: Andy Council testing the 3D drawing software, Filwood Broadway, August 2020 (photographs: Michele Panegrossi)}
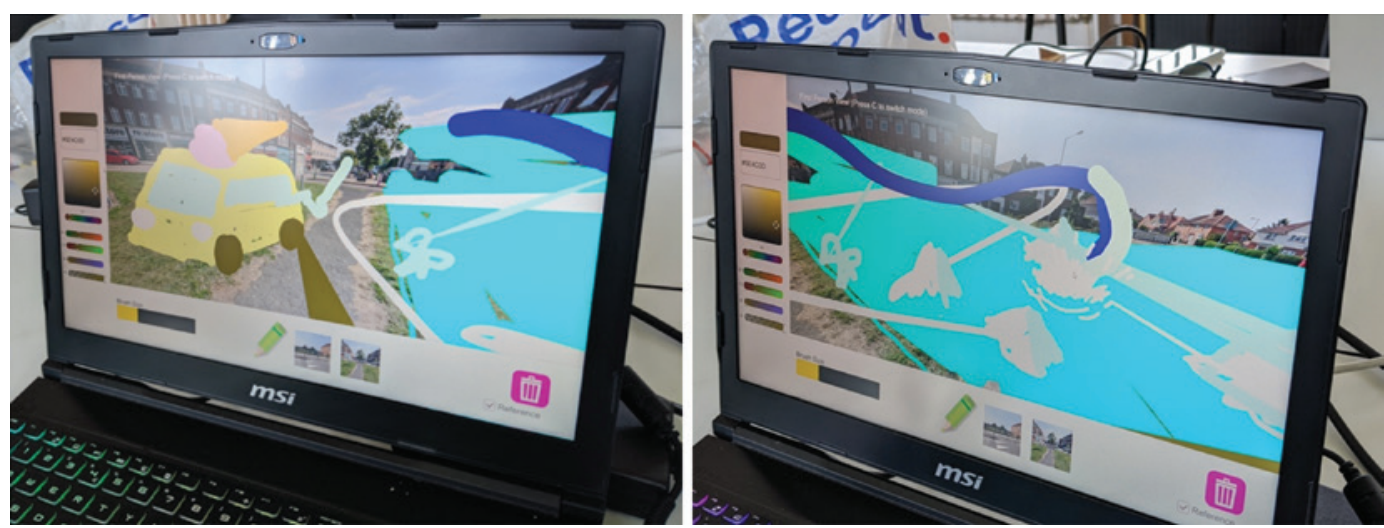
address pragmatics, while others were tailored to the context of the consultation and the specified requirements, such as more residential development. For example:

- How will people get here, get about, or get into the centre of the city and back?

- What about energy: where does the power come from in your future?

- Is there anywhere to work here?

- Where do people live, and are homes here affordable?

- What is there for young people to do, is there somewhere to play, for leisure or recreation?

- Is there any green space?

In our draft structure, we had anticipated that, after taking participants imaginatively into the future, their initial ideas would be highly speculative, not anchored to this place or constrained, and hence that there might not be a believable path to their utopian no-places. We planned to co-create an otherworldly future together before returning, in conclusion, to concrete, achievable possibilities, asking those assembled: 'What about in five or ten years' time, what would you prefer to see here then? How might we get there, and what are the first steps or changes that could be made?' Instead, we found it necessary to reverse this dramaturgy. Participants started to be more playful once community needs had been named, and they realized that whatever ideas they expressed would appear around them as AR drawings onscreen. For instance, when asked for details about what the playground that they wanted to extend would look like, they described a slide twisting its way down from the roof of the hall of the Community Centre, and a skatepark built on top of the tall art deco buildings of the Broadway. When addressing the issue of connecting the city centre and Bristol's Metrobus to Filwood Community Centre, one group conceived autonomous solar-powered pods, and another a Knowle West narrow-gauge railway run by local volunteers (see Figure 9).

There was a mixture of dramaturgical/structural and technical learnings from this iteration of testing to take forward into the next phase. Positive responses from enthusiastic participants were validating, confirming for us that the approach is engaging and functional. While the groups were inspired to dream up futures for Filwood Broadway, we observed that their hopes tended to be more concrete than those of arts audiences who had participated in the performance Billennium, in Millennium Square and Eindhoven. Not looking as far into the future, or as science fictional, they arose out of, and responded to, real, immediate needs and wants, and they included suggestions for: better retail provision, a bakery, a greengrocer and butcher, a café with pavement tables and a bar, pedestrianizing one lane of the street, a weekly local food and craft market, and a lido where the former swimming pool had been demolished (see Figure 8 and Figure 9).

Our audience in Filwood were local residents or community organizers, so they had a high investment in the area and its future. They also brought with them historical knowledge and information about plans that they were able to feed in. As with co-created knowledge, the ideas proposed will 'be deeper and stronger if ... co-produced with actors' who have a stake in the neighbourhood and the lived expertise of inhabiting a place. As with research, the preferred futures visualized are 'more likely to effect change if [they] are owned by people' in the community and other stakeholders 'who have the capacity to effect change' (Lupton and Dyson, 2015, cited in Campbell and Vanderhoven, 2016: 10).

The collaborative, interprofessional research and development of Future Places Toolkit is still ongoing, so this text records and reflects critically on the prototyping and engagement process so far, sharing learning from the first phase of development that will 
Figure 8: Participants in the AR engagement activity, Filwood Broadway, August 2020 (screenshot: Michele Panegrossi; live AR illustration: Camille Aubry)

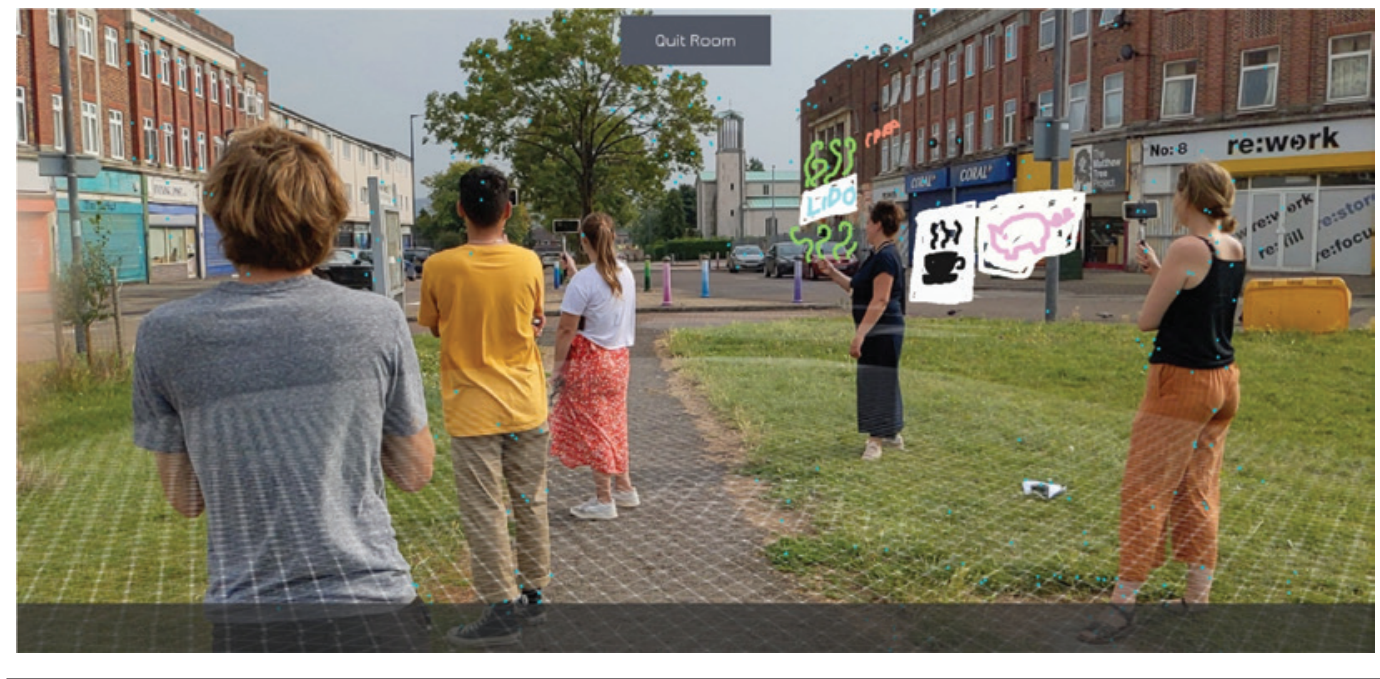

Figure 9: AR drawings, Filwood Broadway, August 2020 (screenshot: Michele Panegrossi; live AR illustration: Camille Aubry)

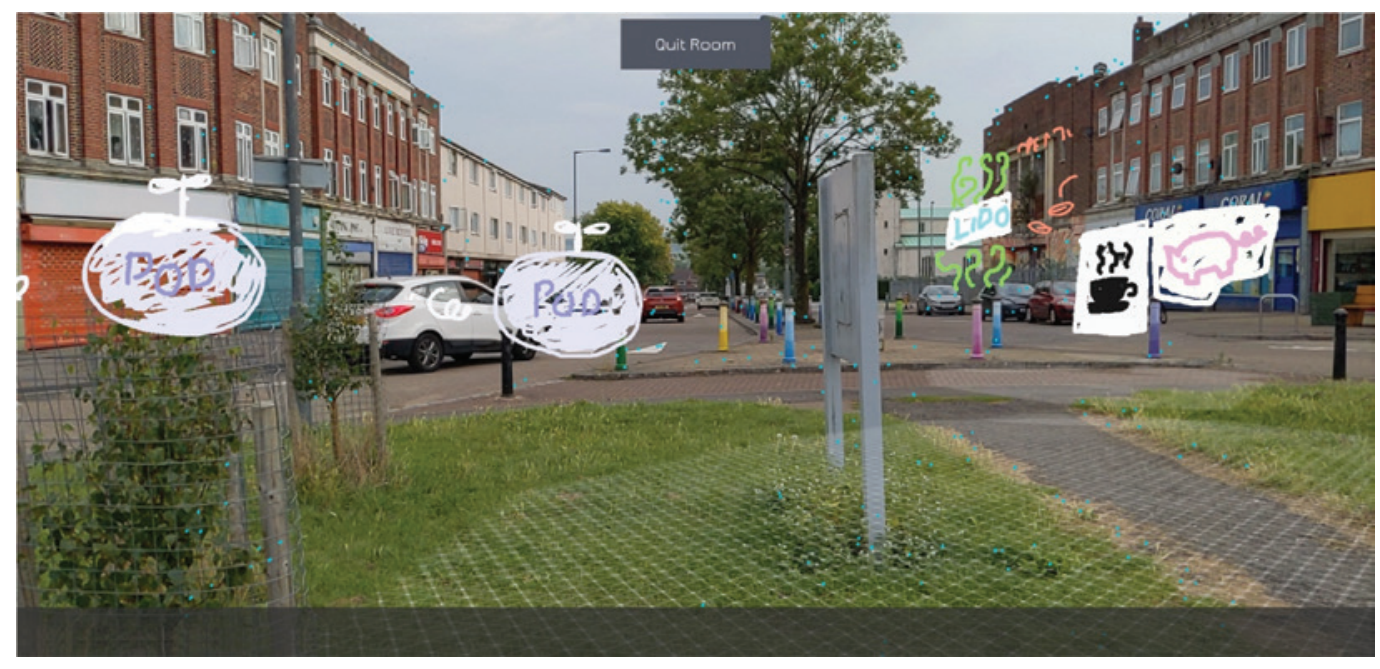

be applicable to other co-produced practice-as-research or knowledge exchange projects that involve partnership working. This learning will also be taken forward into our next iteration of testing with industry, creative and community partners. Over summer 2021, we plan to collaborate with the newly formed Filwood Broadway Working Group to test the AR toolkit with local residents, councillors and architects as they explore improvements to their neighbourhood and 'development for the future that is community driven and inspired', as the terms of reference of the working group put it (Filwood Broadway Working Group, 2021: 1). The aim is to help support a wide range of members of this community - including young people - to imagine and visualize ways to remake the Broadway.

\section{Conclusion: Social imagining and how to future equitably}

The research questions outlined in the introduction are being answered through the practical process of iteratively testing Future Places Toolkit with collaborators, communities and partners. After designers Dunne and Raby (2013: 86, 2-3), we are 
addressing whether asking 'what if?' and visualizing speculative architecture can facilitate debate about 'the kind of future people want, and ... do not want'. Through community engagement, we are exploring whether coming up with science-fiction scenarios gets people thinking critically about the places in which they live and enables them to do 'social dreaming' together (Dunne and Raby, 2013: 6). In our case, we aim to provide a digital 'platform for ... collaborative speculation' and, like Dunne and Raby (2013: 6), hope that through 'speculating more at all levels of society, and exploring alternative scenarios, reality will become more malleable and ... we can help set in place today factors that will increase the probability of more desirable futures'.

With Future Places Toolkit, the alternative plans that community groups describe materialize on their smartphone screens, and thus the changes they want to see become more tangible possibilities. The hope is that this could lead to a greater sense of civic and social agency in change-making outside the engagement activity, empowering participants to get more involved in civic processes such as planning, and to take concrete steps towards their preferred local futures.

To return to performance studies and Lavender's (2016: 26) definition of 'engaged performance', the Future Places Toolkit activity 'provide[s] a seeing place'. In this case, the theatron is the site viewed through the frame of mobile devices and overlaid with AR. In this hybrid space, 'matters of significance' for the future of the place 'are shared communally' between those gathered and involved, in a 'socially committed' way (Lavender, 2016: 26). As Lavender (2016: 27) suggests, the aim is that Future Places Toolkit can 'get in amid social [and civic] processes'. In Jen Harvie's (2013: 124) terms, we hope that Future Places Toolkit can be considered a 'micro-utopian intervention', a 'provocation [for people] to reconsider' their neighbourhood, and also an intervention into conventional planning processes (see also Dolan, 2005).

My digital placemaking research, which I have outlined here, has focused on using digital means to convene people to imagine better futures for their local neighbourhoods. Above, I asked critical questions about the aspiration to improve or 'make places better' with digital placemaking. The same issues come up when imagining 'better futures', and we need to keep asking, better for whom? Just as we must be responsible when developing digital apps and tools, in order that we do not create barriers to access, we should develop inclusive ways of futuring, and envision equitable futures. We need to be attentive to who has the privilege - the time and space - to speculate, and who is included in each future. Who is involved and who gets excluded from processes of visioning, and the futures that are imagined?

In this article, I have described the process of co-creating and iteratively developing a set of live and AR visioning tools with collaborators, partners and communities. In relation to the issues raised, this engaged research project aims to give people who are representative of local neighbourhoods the agency to narrate themselves into times to come, and to see themselves in their preferred futures. As Anab Jain of Superflux says, we also 'hope that through the lens of the future', Future Places Toolkit helps people 'reflect better on the present, on the decisions and the actions we take today, on where we want to be', and on what we can do to get there (Jain and Candy, 2019: 99).

\section{Funding}

- The Creative Industries Clusters Programme managed by the Arts and Humanities Research Council as part of the Industrial Strategy.

- The Knowledge Exchange Fund, Research and Enterprise Development (RED), University of Bristol. 


\section{Acknowledgements}

Creative collaborators:

- Jessica Hoffmann (Uninvited Guests) and sound artist Duncan Speakman

- Creative technologists Michele Panegrossi and Luca Biada (Fenyce)

- Animations and live illustrations by Sam Steer, with live sketches in Filwood by Andy Council and Camille Aubry.

Partners:

- Architects Stride Treglown

- We Can Make/Knowle West Media Centre.

\section{Notes on the contributor}

Paul Clarke is a senior lecturer in performance studies at the University of Bristol, UK, and directs the theatre company Uninvited Guests. Founded over twenty years ago, the company's work tours nationally and internationally. Focusing mainly on participatory performance, they also make theatrical guided tours and design experiences that integrate emerging technologies, apps and locative devices. He is a Digital Placemaking Fellow on Bristol+Bath Creative R+D, an AHRC Creative Cluster, and Faculty of Arts Partnership Fellow at the University of Bristol.

\section{References}

Bristol+Bath Creative R+D (n.d.a) 'About'. Accessed 1 November 2020. https://bristolbathcreative. org/about.

Bristol+Bath Creative R+D (n.d.b) 'Digital placemaking'. Accessed 1 November 2020. https://bristolbathcreative.org/pathfinders/digital-placemaking.

Brown, S. (2019) Consequence Scanning: An Agile practice for responsible innovators. London: Doteveryone. Accessed 26 June 2021. www.doteveryone.org.uk/project/consequencescanning/.

Campbell, H.J. and Vanderhoven, D. (2016) Knowledge That Matters: Realising the potential of coproduction. Manchester: N8 Research Partnership/ESRC.

Clarke, P., Hoffmann, J., Speakman, D., Steer, S., Panegrossi, M. and Biada, L. (2020) Future Places Toolkit (prototype). Accessed 26 June 2021. www.youtube.com/watch?v=5ocFOBXhxsc.

Cohen-Cruz, J. (2010) Engaging Performance: Theatre as call and response. London: Routledge.

cprime (n.d.) 'What is agile? What is scrum?' Accessed 1 November 2020. www.cprime.com/ resources/what-is-agile-what-is-scrum/.

Dolan, J. (2005) Utopia in Performance: Finding hope at the theater. Ann Arbor: University of Michigan Press.

Doteveryone (2020) 'About: Five years fighting for better tech, for everyone'. Accessed 1 November 2020. https://doteveryone.org.uk/about/.

Dunne, A. and Raby, F. (2013) Speculative Everything: Design, fiction, and social dreaming. Cambridge, MA: MIT Press.

ENoLL (European Network of Living Labs) (n.d.) 'About: What are living labs?' Accessed 1 November 2020. https://enoll.org/about-us/.

Filwood Broadway Working Group (2021) Terms of Reference. Unpublished.

Greenfield, A. (2017) Radical Technologies: The design of everyday life. London: Verso.

Harvie, J. (2013) Fair Play: Art, performance and neoliberalism. Basingstoke: Palgrave.

Horvath, C. and Carpenter, J. (2020) 'Introduction: Conceptualising co-creation as a methodology'. In C. Horvath and J. Carpenter (eds), Co-Creation in Theory and Practice: Exploring creativity in the Global North and South. Bristol: Policy Press, 1-22.

Jackson, S. (2011) Social Works: Performing art, supporting publics. New York: Routledge.

Jain, A. and Candy, S. (2019) 'Critical activism: Interview'. Journal of Futures Studies, 23 (3), 99-104. https://doi.org/10.6531/JFS.201903_23(3).0008. 
King, M., Mean, M. and Stewart-Hall, R. (2020) 'We can make: Co-creating knowledge and products with local communities'. In C. Horvath and J. Carpenter (eds), Co-Creation in Theory and Practice: Exploring creativity in the Global North and South. Bristol: Policy Press, 207-20.

Lavender, A. (2016) Performance in the Twenty-first Century: Theatres of engagement. Abingdon: Routledge.

Make:Good (n.d.) 'About'. Accessed 1 November 2020. https://make-good.com/about/.

Morrison, J. (n.d.) 'Digital Placemaking Guide', Calvium resources. Accessed 25 June 2019. https://calvium.com/resources/digital-placemaking/.

Pearson, M. (2010) Site-Specific Performance. Basingstoke: Palgrave Macmillan.

Pritchard, S. (2016) 'Creative placemaking, or a violently anti-working-class vision of the urban pastoral', Colouring in Culture blog. Accessed 24 June 2019. http://colouringinculture.org/ blog/violentcreativeplacemaking?rq=placemaking.

RIBA (Royal Institute of British Architects) (2020) Plan of Work 2020. London: RIBA. Accessed 26 June 2021. www. architecture.com/-/media/GatherContent/Test-resources-page/Additional-Docu ments/2020RIBAPlanofWorkoverviewpdf.pdf.

Stride Treglown (n.d.) 'Shaping future places'. Accessed 1 November 2020. https://stridetreglown. $\mathrm{com} /$ initiatives/shaping-future-places/.

Stride Treglown (2018) The Little Book of Provocations: Shaping future places. Bristol: Stride Treglown.

The Knowledge (2021) 'Filwood Broadway', Knowle West Community Website. Accessed 11 June 2021. www.knowlewest.co.uk/regeneration/filwood-broadway/.

Tsing, A.L. (2012) 'On nonscalability: The living world is not amenable to precision-nested scales'. Common Knowledge, 18 (3), 505-24. https://doi.org/10.1215/0961754X-1630424.

Tsing, A.L. (2015) The Mushroom at the End of the World: On the possibility of life in capitalist ruins. Princeton, NJ: Princeton University Press.

UKRI (UK Research and Innovation) Arts and Humanities Research Council (n.d.) 'The Creative Industries Clusters Programme'. Accessed 1 November 2020. ahrc.ukri.org/innovation/creativeeconomy-research/the-creative-industries-clusters-programme/.

Uninvited Guests and Speakman, D. (2018) Billennium. Accessed 26 June 2021. www.youtube.com/ watch?v=A001vjHvmo4. 